\title{
Current status of functional imaging in neuroblastoma, pheochromocytoma, and paraganglioma disease
}

\author{
Alexander Stephan Kroiss
}

Received: 11 June 2018 / Accepted: 12 August 2018 / Published online: 4 September 2018

(C) The Author(s) 2018

Summary Diagnostic imaging plays an important role in the detection of paraganglioma (PGL), pheochromocytoma (PCC), and neuroblastoma (NB). Anatomic imaging, for example CT or MRI, offers high sensitivity in these neuroendocrine tumors (NET) but only moderate specificity, often associated with difficulties in clearly distinguishing between NET and non-NET. Functional imaging, as in the use of different radioisotopes, is indispensable in oncological imaging. The introduction of PET and PET/CT, respectively, led to a dramatic improvement in both malignant and nonmalignant PGL, PCC, and NB, assessing the exact tumor extent. This review gives an overview of functional and anatomical imaging in PGL, PCC, and NB.

Keywords Glomus tumor - neuroendocrine tumors · $\mathrm{PET} \cdot \mathrm{CT} \cdot \mathrm{MR}$

\section{Aktueller Stellenwert der funktionellen Bildgebung beim Neuroblastom, Phäochromozytom und Paragangliom}

Zusammenfassung Die diagnostische Bildgebung spielt eine bedeutende Rolle bei der Erkennung eines Paraganglioms (PGL), Phäochromozytoms (PCC) und Neuroblastoms (NB). Bei der anatomischen Bildgebung, z.B. Computertomographie (CT) oder Magnetresonanztomographie (MRT), besteht eine hohe Sensitivität für diese neuroendokrinen Tumoren (NET), aber nur eine mäßig hohe Spezifität, die oft mit Schwierigkeiten einhergeht, eine klare Unterscheidung zwischen NET und Nicht-NET zu treffen. Funktionelle Bildgebung, wie beim Einsatz verschie-

\section{A. S. Kroiss, MD ( $\varangle)$}

Department of Nuclear Medicine, Medical University Innsbruck, Anichstraße 35, 6020 Innsbruck, Austria alexander.kroiss@i-med.ac.at dener Radioisotope, ist unerlässlich für die onkologische Bildgebung. Die Einführung der Positronenemissionstomographie (PET) bzw. der PET-CT führte zu einer deutlichen Verbesserung sowohl bei malignen als auch bei nichtmalignen PGL, PCC und NB in Bezug auf die Bestimmung der exakten Tumorausdehnung. Die vorliegende Übersichtsarbeit bietet einen Überblick über die funktionelle und anatomische Bildgebung bei PGL, PCC und NB.

Schlüsselwörter Glomustumor · Neuroendokrine Tumoren · PET $\cdot$ CT $\cdot$ MR

\section{Introduction}

Tumors of the neural crest have a wide range of clinical presentations. These neuroendocrine tumors (NET) - with the ability to overexpress somatostatin (SST)-are referred to as pheochromocytoma (PCC) and neuroblastoma (NB) if they arise from the chromaffin cells of the adrenal medulla, whereas extraadrenal tumors arising from the (para) sympathetic nervous system are known as paraganglioma (PGL). These tumors can be found anywhere from the neck to the pelvis [1]. Because of their neuroendocrine origin, most abdominal and thoracic extra-adrenal PGL produce catechol amines and related substances, whereas head and neck PGL (HNPGL) usually do not produce such substances [2]. Compared to HNPGL, which are usually of parasympathetic origin, extracervical PGL, PCC, and NB are associated with sympathetic ganglia.

Due to the high vascularization rate of these NET, a biopsy often cannot be performed in clinical routine. Therefore, diagnostic imaging is crucial to predict the exact tumor extent, foremost in metastatic disease. 
Fig. 1 29-year-old male patient suffering from malignant pheochromocytoma was referred for staging after surgery. Compared to planar anterior (a) and posterior (b) ${ }^{123} \mathrm{I}-\mathrm{MIBG}$ images, ${ }^{68}$ Ga-DOTA-TOC PET maximum intensity projection image (c) clearly depicts more lesions-confirmed by anatomical imaging - as bone metastases. In addition, bone lesions seen by PET were more readily detectable than by planar 123I-MIBG imaging (circle in $\mathbf{a}$ and $\mathbf{c}$ )

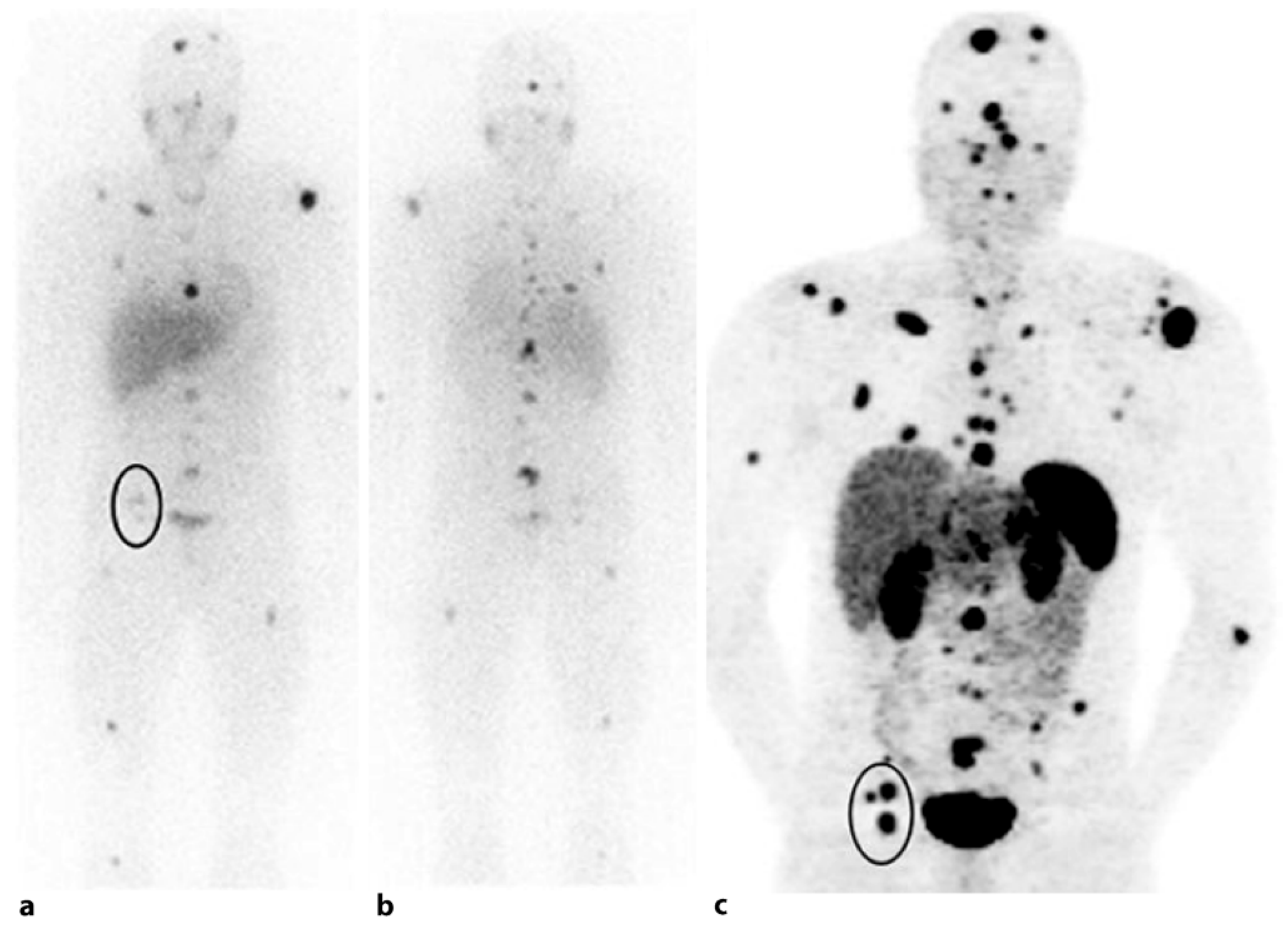

\section{Conventional scintigraphy}

123/-MIBG: non-metastatic PCC/PGL and NB

Anatomical imaging serves as the first-line modality in the locoregional staging of these tumors. Morphological imaging, such as CT or MRI, provides excellent anatomical detail and high sensitivity (100\%; [2]), but lacks specificity as difficulties may occur when distinguishing between tumors derived from the sympathetic nervous system and other tumor entities [1]. Compared to MRI, CT offers less motion artefacts and better spatial resolution. On the other hand, MRI provides better soft tissue contrast than does CT, renouncing the use of ionic intravenous contrast agents which can lead to side effects such as allergic reactions, hypertensive crisis, or nephropathy.

\section{Functional imaging}

In contrast to CT and MRI, functional imaging modalities serve as a useful diagnostic tool for distinguishing between viable tumor and a nonviable residual lesion without being affected by anatomical distortion after surgery or irradiation, which is a limitation of anatomical imaging. Compared with anatomical imaging, radionuclide imaging (conventional scintigraphy, PET) shows both high sensitivity and specificity, distinguishing between scars and tumor recurrence after previous surgery.
Attempts to image PCC and NB by specific radiotracer techniques began with the development of metaiodobenzylguanidine (MIBG) in 1980. MIBG acts as a functional analogue of norepinephrine in following the so-called uptake-1 pathway in adrenergic cells, being stored in granules and released by exocytosis [3]. Labelled with ${ }^{123}$ I, MIBG has become the standard in clinical practice due to the favorable characteristics of the labelling radioisotope ${ }^{123}$ I, with its shorter half-life, higher emitted photon flux, and lack of beta particulate emission as compared to ${ }^{131}$ I [3]. Radiolabeled MIBG has to be administered by slow intravenous injection after thyroid blockade (either with sodium perchlorate or potassium iodide orally beginning 1 day before tracer injection and continuing for 5-7 days). To avoid false-negative results, drugs that are known or expected to reduce MIBG accumulation have to be withdrawn for 48 to $72 \mathrm{~h}$ prior to imaging, such as tricyclic antidepressants, reserpine, or sympathomimetic amines $[1,4,5]$. ${ }^{123}$ [MIBG provides valuable prognostic information before/after ${ }^{131}$ I-MIBG therapy in these NET [3]. ${ }^{123}$ IMIBG has been found to be highly sensitive and specific in non-malignant PCC and extra-cervical PGL (84\% and $100 \%, 75 \%$ and $100 \%$, respectively; $[2,6]$ ). Reported sensitivity/specificity of ${ }^{123}$ I-MIBG scintigraphy was found to be $87 \%$ and $96 \%$, respectively, for detecting NB $[7,8]$.

Compared to ${ }^{123}$ I-MIBG planar whole-body imaging single photon emission computed tomography 

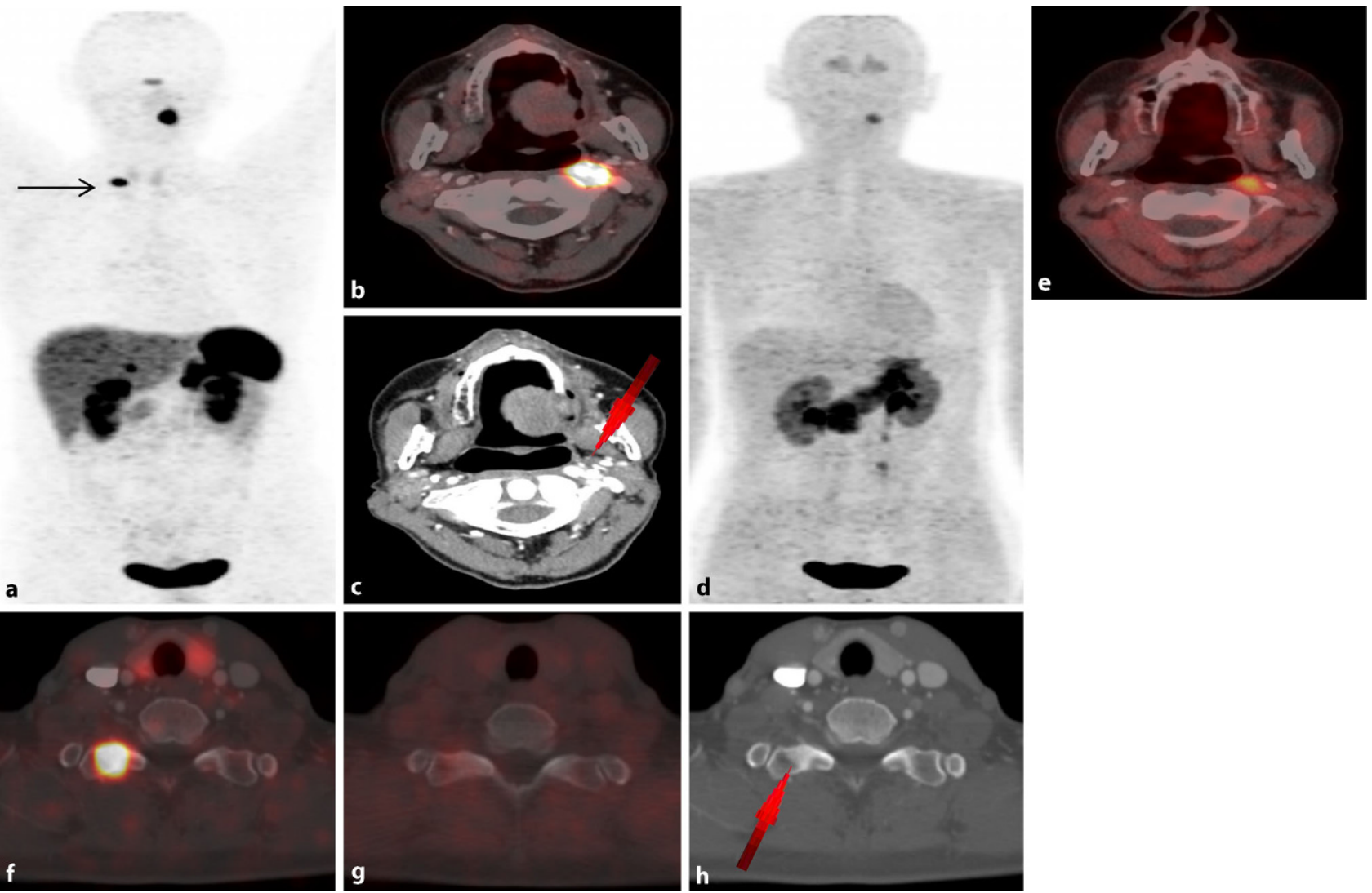

Fig. 2 A 49-year-old woman with malignant extra-adrenal PGL disease. Maximum intensity image (a) and transverse image (b) showed intense focal ${ }^{68} \mathrm{Ga}$-DOTA-TOC uptake, confirmed by diagnostic CT image-consistent with head and neck paraganglioma (c red arrow) - and concordant with ${ }^{18} \mathrm{~F}$ DOPA PET maximum intensity image (d) and transverse image (e). The additional intense focal ${ }^{68} \mathrm{Ga}$-DOTA-TOC uptake (a black arrow) was identified as a small area of sclerosis in the

(SPECT) and combined SPECT/CT may increase sensitivity in both, PCC and PGL [2, 3]. However, lesions beyond the diameter of $1 \mathrm{~cm}$ can be missed by both ${ }^{123}$ I-MIBG and SPECT [2].

An additional reason for this discrepancy can be explained on a molecular level: PGL may undergo dedifferentiation, leading to a loss of norepinephrine transporter or vesicular monoamine transporter (VMAT), which could then lead to false-negative findings in metastatic disease [2], concluding that particularly NET of parasympathetic origin (HNPGL) are not suitable for ${ }^{123}$ I-MIBG imaging [9].

\section{1/n-octreotide: HNPGL}

SST is a peptide hormone containing 14 amino acids. In 1982, the long-acting SST analogue octreotide was synthesized, which can be used for therapy by blocking the excessive hormone production by NET [4]. To date, five receptor subtypes have been characterized that are G protein-coupled and able to bind SST. Abundant expression of SST is characteristic of NET,

transverse processes of the first thoracic vertebra (f). The ${ }^{18} \mathrm{~F}$ DOPA PET image showed no osseous lesion (g). After ${ }^{68} \mathrm{Ga}-$ DOTA-TOC PET/CT fusion (f), a small area of sclerosis was detected in the right transverse process of the first thoracic vertebra (arrow), which was confirmed as osteoblastic metastasis (h). ${ }^{68} \mathrm{Ga}$-DOTA-TOC PET/CT fusion changed the tumor staging from primary tumor to metastatic disease in this patient

with overexpression of SST receptor subtype 2 in most NET.

Planar and SPECT imaging using ${ }^{111}$ In-diethylenetriaminepentaacetic acid octreotide ( ${ }^{111} \mathrm{In}$-octreotide) is an accepted functional imaging modality for the diagnosis of SST-positive NET, particularly for HNPGL $[4,9]$. Similar to ${ }^{123}$ I-MIBG, ${ }^{111}$ In-octreotide offers pretherapeutic staging for peptide receptor radionuclide therapy (PRRT) in NET [4], particularly useful in surgically inoperable tumors or metastatic disease. ${ }^{111}$ In-octreotide scintigraphy should be performed not earlier than 6 weeks after the last injection of longacting SST analogue. Koopmans and colleagues reported that both ${ }^{111}$ In-pentetreotide and anatomical imaging (CT/MRI) showed a sensitivity of $93 \%$ in the detection of HNPGL, with that of ${ }^{123}$ I-MIBG imaging being only $44 \%$, suggesting that ${ }^{111}$ In-pentetreotide is a more suitable functional imaging tool for assessing HNPGL disease, particularly when there is high clinical suspicion and negative ${ }^{123}$ I-MIBG scintigraphy [9]. Similar to ${ }^{123}$ I-MIBG, the main disadvantage of ${ }^{111} \mathrm{In}$ - 
Fig. 3 A 58-year-old man with metastatic extra-adrenal PGL disease. The maximum intensity projection image (a) and transverse image (b, d) show intense focal ${ }^{68} \mathrm{Ga}$-DOTATOC uptake in the head and neck area. The diagnostic CT images $(\mathbf{c}, \mathbf{e})$ show strong contrast enhancement, consistent with head and neck paraganglioma(red arrows). The intense focal uptake in the abdomen $(\mathbf{a}, \mathbf{f})$ is confirmed on diagnostic CT images (g red arrow) as being an extra-adrenal, soft tissue paraganglioma lesion. The small focus of ${ }^{68} \mathrm{Ga}$-DOTATOC uptake superior to the left upper lobe of the thyroid gland (a black arrow) is a paraganglioma lesion of the larynx (confirmed by diagnostic CT)
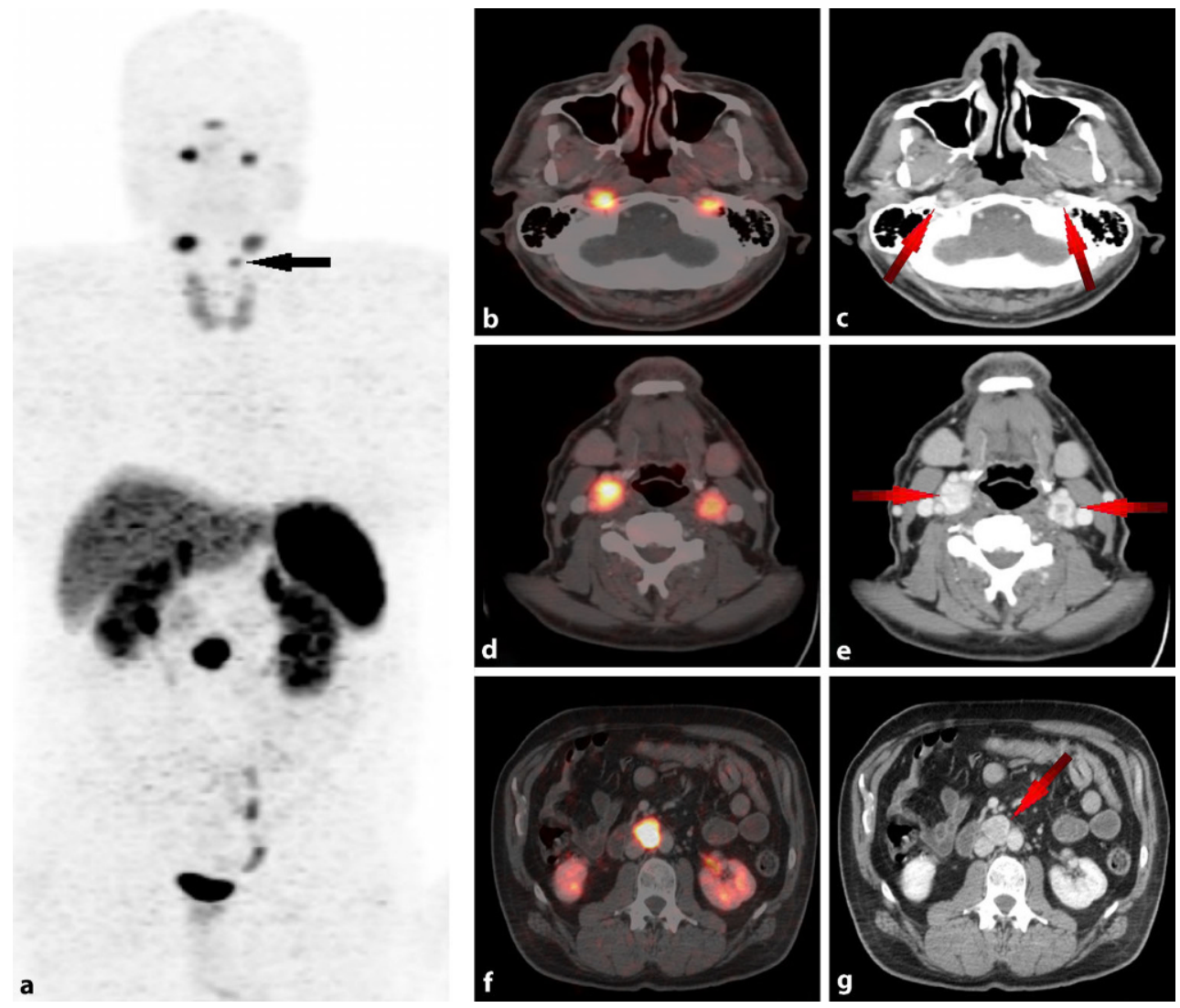

pentetreotide scintigraphy remains the inherently limited spatial resolution of SPECT and SPECT/CT.

\section{PET imaging}

The introduction of PET and combined PET/CT into clinical practice including the development of new PET radiopharmaceuticals has produced promising results in the detection of these tumors. Compared to planar scintigraphy and SPECT imaging, PET has a much shorter injection-to-imaging interval, higher spatial resolution (beyond $4-5 \mathrm{~mm}$ ), and a shorter scanning time within $2 \mathrm{~h}$.

\section{${ }^{18}$ F-FDG: genetic mutation of SDHB and negative 123/-MIBG NET}

${ }^{18} \mathrm{~F}$-fluorodeoxyglucose $\left({ }^{18} \mathrm{~F}-\mathrm{FDG}\right)$ is used for the detection and management of many types of tumors in children and adults. ${ }^{18} \mathrm{~F}-\mathrm{FDG}$ portrays the glucose metabolic activity of tumors, and its uptake and retention are unrelated to catecholamine uptake and storage [3]. ${ }^{18} \mathrm{~F}-\mathrm{FDG}$ PET provides high sensitivity in patients with genetic mutation of succinate dehydrogenase subunit B (SDHB) in metastatic disease of PCC and PGL (83\%; [2]).

${ }^{18} \mathrm{~F}-\mathrm{FDG}$ PET appears valuable for the localization of NET which do not accumulate MIBG or other tracers of the sympathetic nervous system [3]. On the other hand, ${ }^{18} \mathrm{~F}-\mathrm{FDG}$ has limited value in the detec- tion of these NET due to uptake in various tumors, leading to decreased specificity $[2,10]$. Taggart DR and colleagues compared functional imaging modalities using ${ }^{18} \mathrm{~F}-\mathrm{FDG}$ and ${ }^{123} \mathrm{I}-\mathrm{MIBG}$ in patients suffering from relapsed NB before and after ${ }^{123} \mathrm{I}-\mathrm{MIBG}$ therapy, and concluded that FDG is not sensitive enough, especially for the detection of bone lesions, because bone marrow may also demonstrate increased ${ }^{18} \mathrm{~F}$-FDG uptake due to bone marrow hyperplasia after myelosuppressive chemotherapy, particularly in advanced stages of NB [11].

\section{${ }^{18}$ F-DOPA: non-metastatic (HN)PGL/PCC and NB}

In contrast to ${ }^{18} \mathrm{~F}$-FDG, ${ }^{18} \mathrm{~F}$-fluoro-L-dihydroxyphenylalanine $\left({ }^{18} \mathrm{~F}\right.$-DOPA) is a very useful radiopharmaceutical for imaging catecholamine-secreting tumors [1], because of the ability of these tumors to take up, decarboxylate, and store amino acids, such as DOPA, and their biogenic amines (dopamine; [12]). Similar to MIBG, dopamine is actively transported via VMAT after uptake into cells by the norepinephrine transporter, being stored in neurosecretory granules of catecholamine-producing cells. In order to visualize small lesions, carbidopa pretreatment can be applied before staging.

Carbidopa is a drug which decreases decarboxylation and subsequent renal clearance of DOPA, leading to an increase of the tumor to background ratio of radiopharmaceutical uptake. In general, carbidopa 


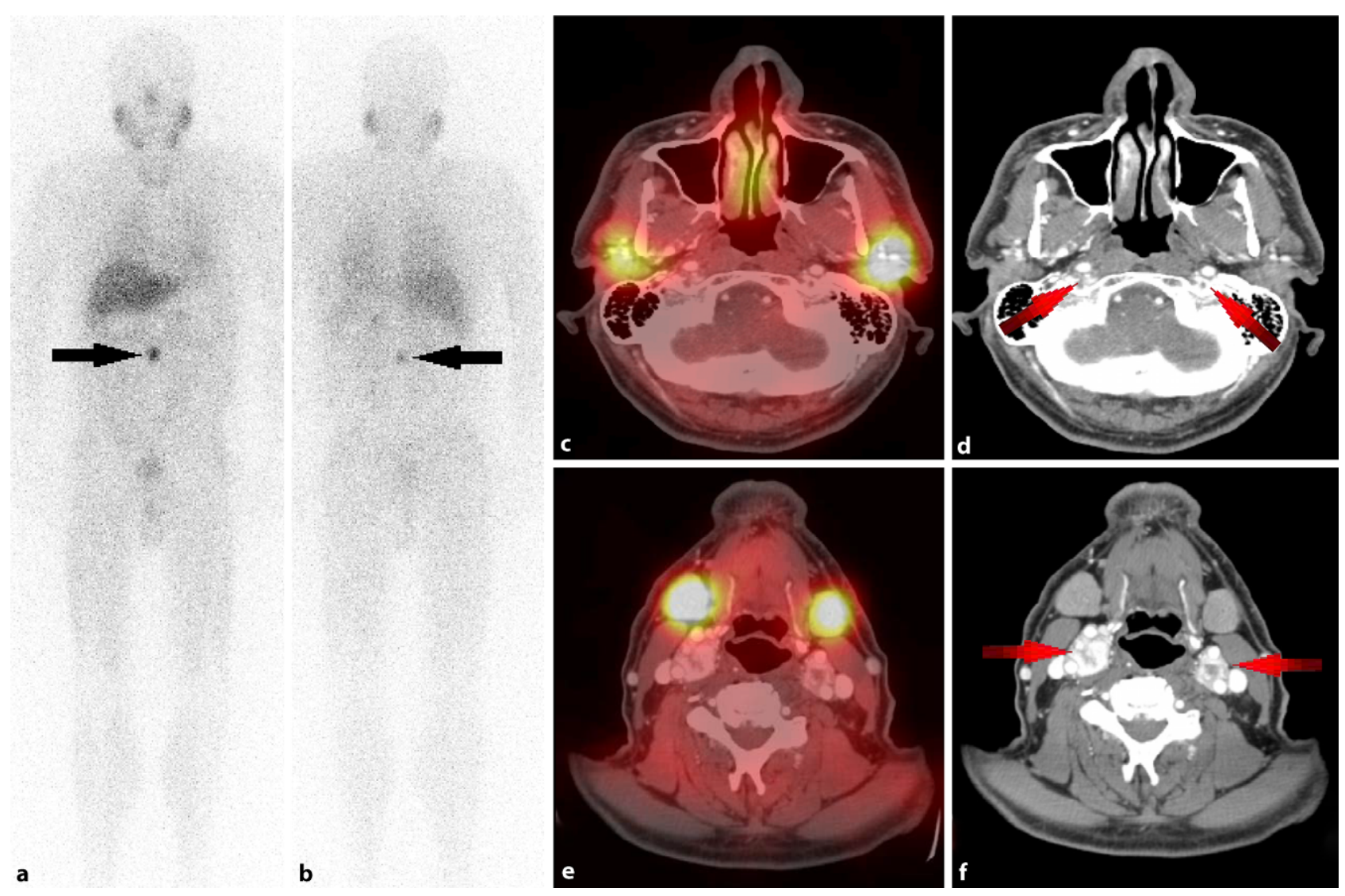

Fig. 4 Additional imaging in the patient seen in Fig. 3 . The intense focal ${ }^{123}$ I-MIBG uptake of the abdomen seen on planar images (a, b black arrows) was confirmed by ${ }^{68} \mathrm{Ga}-$ DOTATOC PET/CT as being a soft tissue paraganglioma lesion (Fig. 3a, f, g). After software-based image fusion of SPECT images with diagnostic CT images, symmetrical physiologi-

pretreatment has a minor effect on lesions depicted by ${ }^{18} \mathrm{~F}$-DOPA PET, because even with carbidopa pretreatment, the performance of ${ }^{18} \mathrm{~F}$-DOPA PET appears to be suboptimal in case of metastatic disease [2].

${ }^{18} \mathrm{~F}$-DOPA offers high sensitivity and specificity for detecting non-metastatic PCC (both 100\%; [6]). However, decreased sensitivity with reference to CT/MRI was reported in metastatic disease of SDHB mutationrelated PCC and PGL (20-45\%; [2, 13]). These differences in ${ }^{18} \mathrm{~F}$-DOPA accumulation between primary tumors and metastases of PCC and PGL were previously reported. This phenomenon is probably due to the fact that metastatic lesions have dedifferentiated cells. This dedifferentiation might lead to loss of specific norepinephrine transporters in these tumors [2].

A recent publication confirmed the superiority of combined functional and anatomical imaging $\left({ }^{18} \mathrm{~F}-\right.$ DOPA PET/CT) over conventional scintigraphy (123IMIBG; [14]) in extra-adrenal PGL of ten patients. In this article by Kroiss A and colleagues, ${ }^{18} \mathrm{~F}$-DOPA PET and diagnostic CT detected all HNPGL, whereas ${ }^{18} \mathrm{~F}$ DOPA PET failed to detect eight bone metastases that were verified by diagnostic CT, resulting in an overall decrease of sensitivity on a per-lesion basis for ma- cal ${ }^{123}$ I-MIBG uptake was observed in the parotid (c) and submandibular (e) glands. All verified head and neck lesions (d, $\mathbf{f}$ red arrows) were ${ }^{123}$ I-MIBG negative (c, e). ${ }^{68} \mathrm{Ga}$-DOTATOC $\mathrm{PET} / \mathrm{CT}$ changed the tumor staging from primary tumor to multifocal disease (Fig. 3)

lignant HNPGL (69.2\%). Combined functional and anatomical imaging $\left({ }^{18} \mathrm{~F}-\mathrm{DOPA} \mathrm{PET} / \mathrm{CT}\right)$ was required to fully delineate the extent of tumor disease, emphasizing the low sensitivity of both planar ${ }^{123}$ I-MIBG and SPECT/CT imaging for malignant HNPGL (5.6\% and $11.1 \%$, respectively; [14]).

For NB in stages 3 and 4, a sensitivity and accuracy of $90 \%$ were reported on a lesion-based analysis for ${ }^{18} \mathrm{~F}$-DOPA PET/CT compared to ${ }^{123} \mathrm{I}-\mathrm{MIBG}$ scintigraphy with $56 \%$ and $57 \%$, respectively [15]. Although no significant difference in terms of specificity was found between the two imaging modalities $\left({ }^{18} \mathrm{~F}-\mathrm{DOPA}\right.$ PET/CT: 75\%; ${ }^{123}$ I-MIBG imaging: $62 \%$ ), the authors recommend ${ }^{18} \mathrm{~F}-\mathrm{DOPA} \mathrm{PET} / \mathrm{CT}$ for $\mathrm{NB}$ taking into account the significant superiority $(p<0.001)$ of detecting soft tissue recurrence/metastases (84\%) and bone lesions (96\%) compared to ${ }^{123}$ I-MIBG scintigraphy $(31 \%$ and $71 \%$; [15]).

\section{${ }^{68} \mathrm{Ga}$-labelled analogues: (non)-metastatic (HN)PGL and metastatic PCC/NB}

The introduction of ${ }^{68} \mathrm{Ga}$-labelled SST analogues (e.g., ${ }^{68} \mathrm{G}$-DOTA-TOC, ${ }^{68} \mathrm{Ga}$-DOTA-NOC, ${ }^{68} \mathrm{Ga}$-DOTA-TATE) 

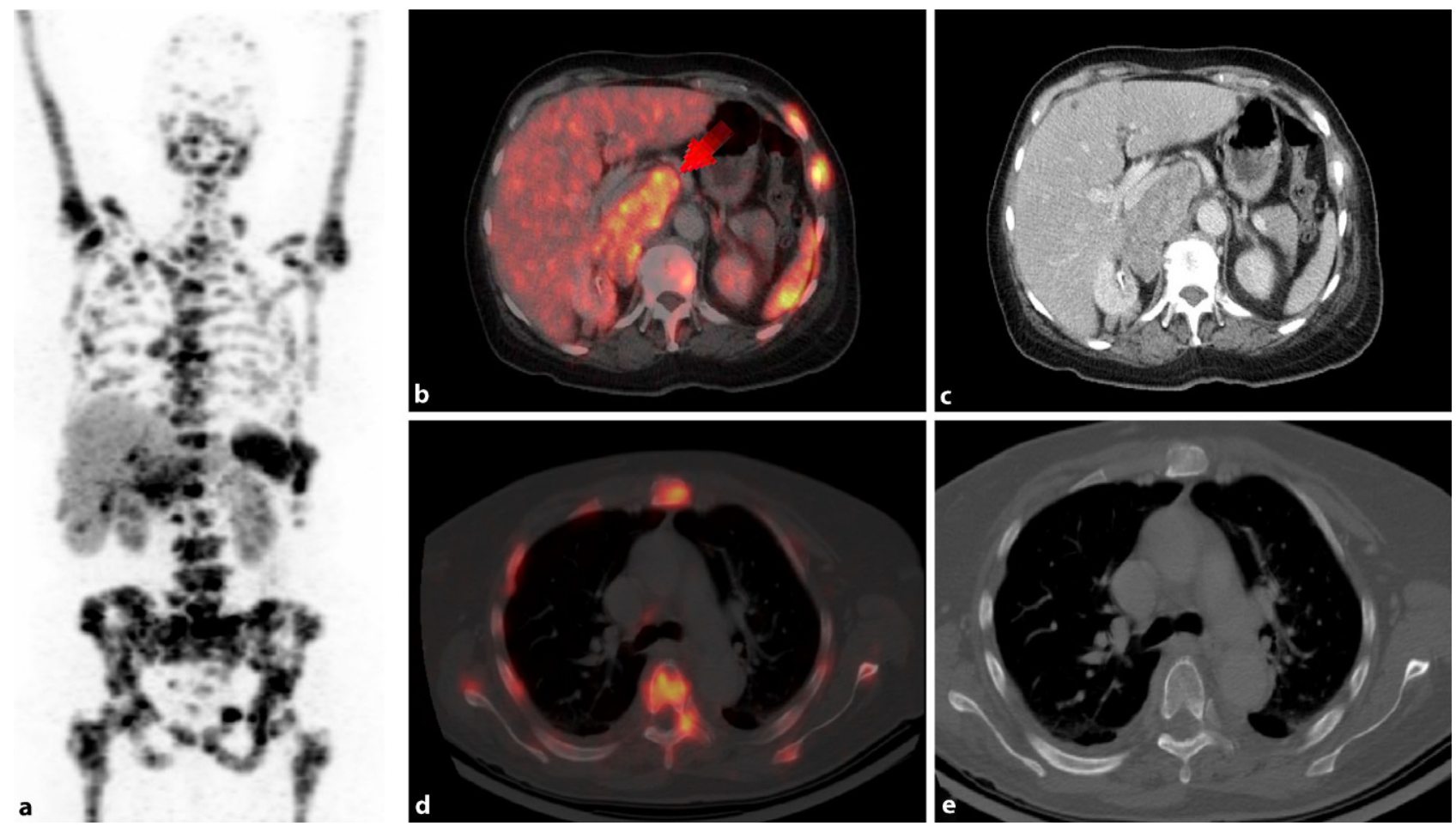

Fig. 5 Imaging of an neuroblastoma recurrence with multiple ${ }^{68} \mathrm{Ga}-\mathrm{DOTA}-\mathrm{TOC}$ PET-positive bone metastases in a $64-$ year old female patient (MIP a). The primary tumor showed a diffuse ${ }^{68} \mathrm{Ga}$-DOTA-TOC uptake in the right upper abdomen (b red arrow), confirmed by diagnostic CT (c). Additional bone

lesions, e.g., in the thoracic vertebra, spine, both scapulae, and rip thorax with intense ${ }^{68} \mathrm{Ga}$-DOTA-TOC uptake were detected by PET (a, b, d), which could not be detected by diagnostic CT (c, e). Combined ${ }^{68} \mathrm{Ga}-\mathrm{DOTATOC}$ PET/CT enabled the exact metastatic tumor staging in this patient

into clinical routine led to a dramatic improvement in sensitivity and specificity for imaging NET [16]. Due to its overall higher counting efficiency and higher spatial resolution, ${ }^{68} \mathrm{Ga}$ PET is a more sensitive detection technique than conventional scintigraphy due to its high SST expression in subtypes 2, 3, and 5 in NET [16]. Due to high physiologic SST expression in both adrenal glands, ${ }^{68} \mathrm{Ga}$-labelled SST analogues may not be suitable for detecting PCC [17]. However, a recent publication showed promising results in the detection of suspected PCC: In contrast to ${ }^{18} \mathrm{~F}$-FDG PET/CT, all primary tumors (nine patients) were correctly identified by ${ }^{68} \mathrm{Ga}$-DOTA-TATA PET/CT and ${ }^{123}$ I-MIBG SPECT/CT compared with postsurgical pathology and follow-up [18].

Our group reported on the high sensitivity of ${ }^{68} \mathrm{Ga}$-DOTA-TOC PET compared to ${ }^{123} \mathrm{I}$-MIBG imaging in both malignant PCC $(91.7 \%$ versus $63.3 \%)$ and NB $(97.2 \%$ versus $90.7 \%)$, with anatomical imaging (CT/MRI) as the reference standard. Additionally, we reported that especially bone metastases were more readily detectable in favor of higher spatial PET resolution compared to planar ${ }^{123}$ I-MIBG imaging (Fig. 1; [19]). The high detection rate of ${ }^{68} \mathrm{Ga}-\mathrm{DOTA}-\mathrm{TOC}$ PET/CT (100\%) compared to ${ }^{123}$ I-MIBG planar (3.4\%) and SPECT/CT (6.9\%) imaging in both non-malignant and malignant HNPGL of ten patients was recently confirmed [20], in line with a previous publication

of Sharma $\mathrm{P}$ and colleagues, who found a significantly lower detection rate for ${ }^{131}$ I-MIBG scintigraphy (38.4\%) compared to ${ }^{68} \mathrm{Ga}-\mathrm{DOTA}-\mathrm{NOC}$ PET/CT $(100 \%)$ in staging of HNPGL [21].

Besides the high accuracy in staging, ${ }^{68} \mathrm{Ga}$-labelled SST analogues give valuable information on tumor cell receptor status in NET when planning PRRT, similar to the information available with ${ }^{123}$ I-MIBG regarding treatment with ${ }^{131}$ I-MIBG [17]. Recent articles confirmed the benefit of combined functional and anatomical imaging (e.g., PET/CT) with change of tumor staging from non-malignant to metastatic disease in these rare NET, most observed for bone metastases (Figs. 2, 3, 4 and 5; [19]).

A recent publication by Janssen I and colleagues showed a lesion-based detection rate of $97.6 \%$ for ${ }^{68} \mathrm{Ga}$-DOTA-TATE PET/CT compared to ${ }^{18} \mathrm{~F}$-DOPA PET/CT (74.8\%), ${ }^{18}$ F-FDG PET/CT (49.2\%), and CT/ MRI (81.6\%) in sporadic malignant PCC and PGL of 22 patients. ${ }^{68} \mathrm{Ga}$-DOTA-TATE detected all bone lesions and lymph nodes of the mediastinum and abdomen. On the other hand, ${ }^{68} \mathrm{Ga}$-DOTA-TATE missed six liver lesions, which were positive on ${ }^{18} \mathrm{~F}-\mathrm{DOPA}$ and anatomical imaging. In addition, five lesions missed on ${ }^{68} \mathrm{Ga}$-DOTA-TATE PET/CT were pulmonary lesions-smaller than $0.6 \mathrm{~cm}$-with four of them positive on ${ }^{18} \mathrm{~F}$-DOPA [22]. In consideration of the limited PET spatial resolution and in addition to ${ }^{68} \mathrm{Ga}$-SST- 
labelled analogues, dedicated MRI and CT imaging of the liver and lungs is needed in order not to miss small metastases [19, 22]. Our group also reported on false-negative liver lesions of PCC and NB patients in both ${ }^{68} \mathrm{Ga}$-DOTA-TOC PET and ${ }^{123}$ I-MIBG imaging, which, however, were positive on CT/MRI [19]. This is in line with publication by Pfluger $\mathrm{T}$ and colleagues who compared ${ }^{123} \mathrm{I}-\mathrm{MIBG}$ imaging to MRI in pediatric $\mathrm{NB}$ [23]. In this context, ${ }^{18} \mathrm{~F}-\mathrm{FDG}$ is a better tool for analyzing this organ $[19,24]$.

A recent publication by Nicolas GP and colleagues compared the sensitivity of ${ }^{68} \mathrm{Ga}$-DOTA-TOC PET/CT to ${ }^{68} \mathrm{Ga}-O P S 202-\mathrm{a}$ novel radiolabeled SST receptor antagonist with high affinity for SST subtype 2-in twelve patients with metastatic gastroenteropancreatic NET. Their results showed a significant higher lesion detection rate for ${ }^{68} \mathrm{Ga}$-OPS202 PET/CT compared to ${ }^{68} \mathrm{Ga}$-DOTA-TOC PET/CT, most observed for liver lesions [25]. In the future, ${ }^{68} \mathrm{Ga}-\mathrm{OPS} 202 \mathrm{PET} / \mathrm{CT}$ may be of high interest for the detection of both metastatic and non-metastatic NET like PCC, PGL, and NB.

\section{Conclusion}

Early detection of PCC, PGL, and NB is crucial and has a major effect on treatment and prognosis, particularly in metastatic disease. Combined functional and anatomical imaging (e.g., PET/CT) is required to fully delineate the extent of NET of both the sympathetic (PCC, extra-adrenal PGL, and NB) and parasympathetic nervous system (HNPGL). Similar to ${ }^{123} \mathrm{I}-\mathrm{MIBG}$, ${ }^{68} \mathrm{Ga}$-labelled SST analogues provide valuable clinical information for planning PRRT in NET, which is particularly useful in patients with surgically inoperable tumors or metastatic disease. Prospective studies with novel combined functional/anatomical techniques (PET/MRI) are required to confirm the specificity of both ${ }^{68} \mathrm{Ga}$-labelled SST analogues and antagonists in these rare NET.

Funding Open access funding provided by University of Innsbruck and Medical University of Innsbruck.

Conflict of interest A.S. Kroiss declares that he has no competing interests.

Open Access This article is distributed under the terms of the Creative Commons Attribution 4.0 International License (http://creativecommons.org/licenses/by/4.0/), which permits unrestricted use, distribution, and reproduction in any medium, provided you give appropriate credit to the original author(s) and the source, provide a link to the Creative Commons license, and indicate if changes were made.

\section{References}

1. Brink I, Hoegerle S, Klisch J, Bley TA. Imaging of pheochromocytoma and paraganglioma. Fam Cancer. 2005;4:61-8.

2. TimmersHJ, ChenCC, CarrasquilloJA, ChenCC, WhatleyM, Ling A, et al. Comparison of 18F-fluoro-L-DOPA, 18F-fluorodeoxyglucose, and 18F-fluorodopamine PET and 123I-
MIBG scintigraphy in the localization of pheochromocytoma and paraganglioma. J Clin Endocrinol Metab. 2009;94:4757-67.

3. Sisson JC, Shulkin BL. Nuclear medicine imaging of pheochromocytoma and neuroblastoma. Q J Nucl Med. 1999;43:217-23.

4. Hoefnagel CA. Metaiodobenzylguanidine and somatostatin in oncology: role in the management of neural crest tumours. Eur J Nucl Med. 1994;21:561-81.

5. Rufini V, Treglia G, Perotti G, Giordano A. The evolution in the use of MIBG scintigraphy in pheochromocytomas and paragangliomas. Hormones (Athens). 2013;12:58-68.

6. Hoegerle S, Nitzsche E, Altehoefer C, Ghanem N, Manz T, Brink I, et al. Pheochromocytomas: detection with 18F DOPA whole body PET—initial results. Radiology. 2002;222:507-12.

7. Shulkin BL, Shapiro B. Current concepts on the diagnostic use of MIBG in children. J Nucl Med. 1998;39:679-88.

8. Leung A, Shapiro B, Hattner R, Kim E, de Kraker J, Ghazzar $\mathrm{N}$, et al. Specificity of radioiodinated MIBG for neural crest tumors in childhood. J Nucl Med. 1997;38:1352-7.

9. Koopmans KP, Jager PL, Kema IP, Kerstens MN, Albers F, Dullart RP. 111In-octreotide is superior to 123I-metaiodobenzylguanidine for scintigraphic detection of head and neck paragangliomas. J Nucl Med. 2008;49:1232-7.

10. Shulkin BL, Hutchinson RJ, Castle VP, Yanik GA, Shapiro B, Sisson JC. Neuroblastoma: positron emission tomography with 2-[fluorine-18]-fluoro-2-deoxy-D-glucose compared with metaiodobenzylguanidine scintigraphy. Radiology. 1996;199:743-50.

11. TaggartDR, Han MM, Quach A, Groshen S, YeW, Villablanca JG, et al. Comparison of iodine-123 metaiodobenzylguanidine (MIBG) scan and [18F]fluorodeoxyglucose positron emission tomography to evaluate response after iodine-131 MIBG therapy for relapsed neuroblastoma. J Clin Oncol. 2009;27:5343-9.

12. Bergström M, Eriksson B, Oberg K, Sundin A, Ahlström $\mathrm{H}$, Lindner $\mathrm{KJ}$, et al. In vivo demonstration of enzyme activity in endocrine pancreatic tumors: decarboxylation of carbon-11-DOPA to carbon-11-dopamine. J Nucl Med. 1996;37:32-7.

13. Treglia G, Cocciolillo F, de Waure C, Di Nardo F, Gualano MR, Castaldi P, et al. Diagnostic performance of 18Fdihydroxyphenylalanine positron emission tomography in patients with paraganglioma: a meta-analysis. Eur J Nucl Med Mol Imaging. 2012;39:1144-53.

14. Kroiss AS, Uprimny C, Shulkin BL, Frech A, Tilg H, Gasser RW, et al. Compared to 123I-MIBG SPECT/CT, 18FDOPA PET/CT provides accurate tumor extent in patients with extra-adrenal paraganglioma. Ann Nucl Med. 2017;31:357-65.

15. Piccardo A, Lopci E, Conte M, Garaventa A, Foppiani L, Altrinetti V, et al. Comparison of 18F-dopa PET/CT and 123I-MIBG scintigraphy in stage 3 and 4 neuroblastoma: a pilot study. Eur J Nucl Med Mol Imaging. 2012;39:57-71.

16. Gabriel M, Decristoforo C, Kendler D, Dobrozemsky G, HeuteD, UprimnyC, etal. 68Ga-DOTA-Tyr3-octreotidePET in neuroendocrine tumors: comparison with somatostatin receptor scintigraphy and CT. J Nucl Med. 2007;48:508-18.

17. Kroiss A, Putzer D, Decristoforo C, Uprimny C, Warwitz B, Nilica B, et al. 68Ga-DOTA-TOC uptake in neuroendocrine tumour and healthy tissue: differentiation of physiological uptake and pathological processes in PET/CT. Eur J Nucl Med Mol Imaging. 2013;40:514-23.

18. Jing H, Li F, Wang L, Wang Z, Li W, Huo L, et al. Comparison of the ${ }^{68} \mathrm{Ga}$-DOTATATA PET/CT, FDG PET/CT, and 
MIBG SPECT/CT in the Evaluation of Suspected Primary Pheochromocytomas and Paragangliomas. Clin Nucl Med. 2017;42:525-9.

19. Kroiss A, Putzer D, Uprimny C, Decristoforo C, Gabriel $\mathrm{M}$, Santner W, et al. Functional imaging in phaeochromocytoma and neuroblastoma with 68Ga-DOTA-Tyr3octreotide positron emission tomography and 123Imetaiodobenzylguanidine. Eur J Nucl Med Mol Imaging. 2011;38:865-73.

20. Kroiss A, Shulkin BL, Uprimny C, Frech A, Gasser RW, Url C, et al. 68Ga-DOTATOC PET/CT provides accurate tumour extent in patients with extraadrenal paraganglioma compared to 123I-MIBG SPECT/CT. Eur J Nucl Med Mol Imaging. 2015;42:33-41.

21. Sharma P, Thakar A, Suman KCS, Dhull VS, Singh H, Naswa $\mathrm{N}$, et al. 68Ga-DOTANOC PET/CT for baseline evaluation of patients with head and neck paraganglioma. J Nucl Med. 2013;54:841-7.

22. Janssen I, Chen CC, Millo CM, Ling A, Taieb D, Lin FI, et al. PET/CT comparing (68)Ga-DOTATATE and other radiopharmaceuticals and in comparison with CT/MRI for the localization of sporadic metastatic pheochromocytoma and paraganglioma. Eur J Nucl Med Mol Imaging. 2016;43:1784-91.

23. Pfluger T, Schmied C, Porn U, Leinsinger G, Vollmar C, Dresel S, et al. Integrated imaging using MRI and 123I metaiodobenzylguanidine scintigraphy to improve sensitivity and specificity in the diagnosis of pediatric neuroblastoma. Ajr Am J Roentgenol. 2003;181:1115-24.

24. Howman-Giles R, Shaw PJ, Uren RF, Chung DK. Neuroblastoma and other neuroendocrine tumors. Semin Nucl Med. 2007;37:286-302.

25. Nicolas GP, Schreiter N, Kaul F, Uiters J, Bouterfa H, Kaufmann J, et al. Sensitivity comparison of ${ }^{68}$ ga-OPS202 and ${ }^{68}$ ga-DOTATOC PET/CT in patients with gastroenteropancreatic neuroendocrine tumors: a prospective phase II imaging study. J Nucl Med. 2018;59:915-21.

26. Kroiss A, Putzer D, Frech A, Decristoforo C, Uprimny C, Gasser RW, etal. Aretrospective comparison between 68GaDOTA-TOCPET/CTand 18F-DOPAPET/CTinpatientswith extra-adrenal paraganglioma. Eur J Nucl Med Mol Imaging. 2013;40:1800-8. 